\title{
The Calibration of Wide Range Meter Based on ML610Q495
}

\author{
Wang Nan \\ Liaoning JIANZHU Vocational University, Liaoyang, Liaoning, 111000, \\ China
}

120211846@qq.com

\begin{abstract}
.
According to the problem that introduces the design of smart meters, which is based on ML610Q495 microcontroller and IDT90E23 measurement chip. This meter has the characteristics of wide range measuring and high accuracy RTC. In the range of $0.02 \mathrm{~A} \sim 100 \mathrm{~A}$ current, the meter's measuring accuracy is below $\pm 0.2 \%$, and in the range of $-45^{\circ} \mathrm{C} \sim+85^{\circ} \mathrm{C}$ temperature the meter's RTC accuracy is below $\pm 0.1 \mathrm{~s} / \mathrm{d}$. This design can meet all the requirements of the State Grid, China Southern Power Grid, and Neimenggu Power Grid, and the meters have passed the test.
\end{abstract}

Keywords: Wide Range Meter, Error Calibration, High Accuracy RTC, RTC Calibration

\section{Introduction}

With the comprehensive construction of smart power grids nationwide, the requirements of the electric energy meter are higher, especially for the range and the clock requirements of electric energy meter is further improved. At present, the State Grid Corporation of China unified bidding requirements 5 (60) A specifications of electric energy meter, China Southern Power Grid requires a minimum current detection for $2 \%$ IB. However, Inner Mongolia power requirement of 1 (100) A specifications of electric energy meter. The intelligent electric energy meter development view cannot reach such a wide range of requirements at present. This paper designs a kind of intelligent electric meter scheme based on ML610Q495+IDT90E23. The scheme measurement accuracy not only can meet the detection requirements, and reference clock error is better than that of the correlation detection requirements, but also its cost low. 


\section{Hardware of intelligent electric energy meter}

The system structure of the intelligent electric energy meter is shown in Figure 1. The ML610Q495 chip of company Rohm was used in microprocessor systems. The chip has an internal real time clock and also has the smart card interface, $\mathrm{I}^{2} \mathrm{C}$, SPI, UART and other hardware interface. Measurement circuit using the measurement of special IDT90E23 chip of IDT Company. The special chip is connected to MCU via SPI bus and MCU. The measurement dynamic range of the chip is from 5000 to 1 . It has software calibration function, and can configure to the metering method of the live wire and zero line. IC card interface circuit and safety certification circuit directly connected through the smart card interface and MCU. The smart card interface conforms to the ISO7816 standard, which can be directly with ESAM and IC card communication. Memory circuit and display circuit are connected by $\mathrm{I}^{2} \mathrm{C}$ bus and $\mathrm{MCU}$.

\section{Intelligent electric meters of calibration}

\section{A. Measurement calibration}

Constant of high frequency pulse. Constant of high frequency pulse is the threshold accumulated by the chip internal electrical energy. When the cumulative power inside of the chip is larger than the constant high frequency pulse, The IDT90E23 chip can output a pulse to the MCU. Constant of FM pulse, calculated by Eq.1, and we write the results into the PLconst_H and PLconst_L registers of measurement chip.

$P L \_$Const $=\frac{838860800 \times G L \times R u}{M C \times R}$

Among them, $P L_{-}$Const is the constant of high frequency pulse, $G L$ is the gain multiple of measurement chip, $\mathrm{Ru}$ is the resistance value of shunt, $M C$ is the constant of electric energy meter pulse, $\mathrm{R}$ is the total resistance of the divider resistance. 


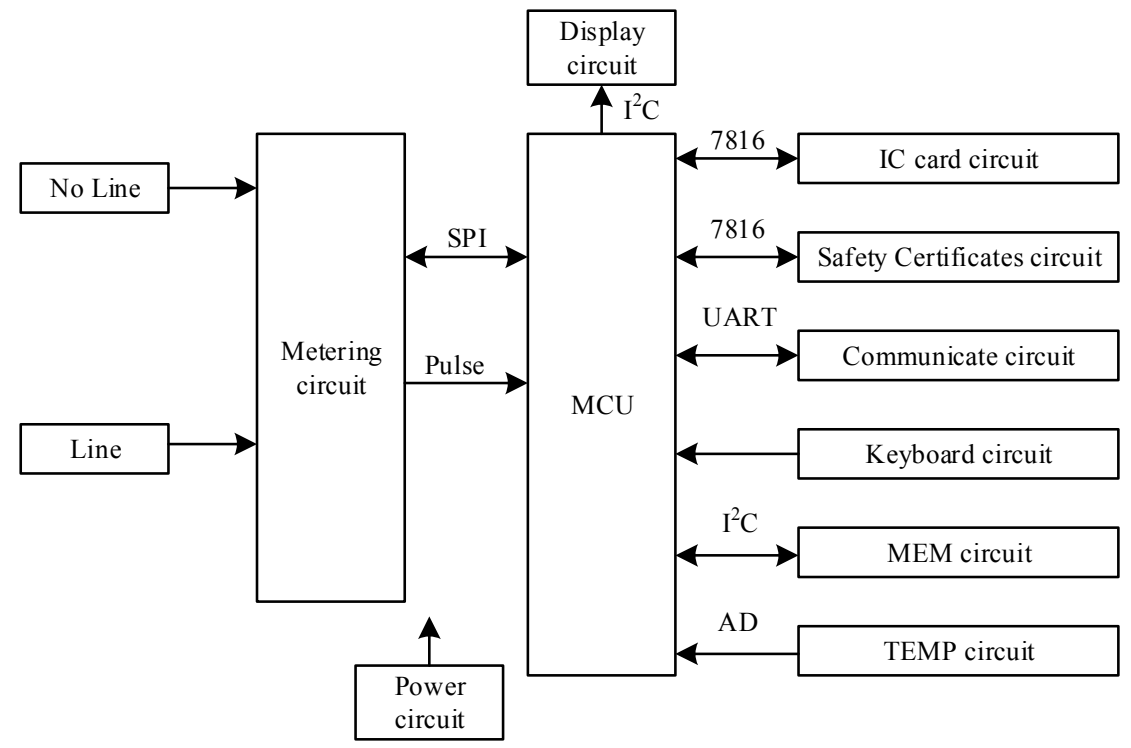

Fig.1 System structure diagram

Reference point error correction. Reference point error correction is the error of electric energy meter fixed electric energy meter in 1.0 phases $100 \% I_{b}$ current. Gauged meter gain calculated by Eq. 2 and the results wrote in the $L_{\text {gain }}$ registry. $L_{\text {Gain }}=\frac{e \times 2^{15}}{1+e}$

Among them, $L_{\text {Gain }}$ is gauged meter gain is the error of electric energy meter in 1.0 phase $100 \% I_{b}$ current.

Phase correction. Phase correction is the error of electric energy calibration of $0.5 \mathrm{~L}$ phase $100 \% I_{b}$ current meter. The meter calibration angle error can be calculated by Eq.3, and write the results in the $\mathrm{L}_{\text {phi }}$ register.

$L_{P h i}=e_{L} \times 3763.74$

Among them, $L_{P h i}$ is a check meter error. $e_{L}$ is the error value of $0.5 \mathrm{~L}$ phase $100 \% I_{b}$ current of electric energy meter.

The voltage effective value calibration. The voltage effective value gains, according to 4 calculation formula, and write the results into the organ register.

$$
U_{\text {gain }}=\operatorname{int}\left(\frac{26400 \times U_{n}}{\text { Vol_mea }}\right)
$$

Among them, $U_{\text {gain }}$ is the voltage gain coefficient. $U_{n}$ is a reference voltage. Vol_mea is the effective value register value of a voltage measurement chip. 
Current effective value calibration. The effective value of current gain calculated according to Eq.5, and writes the results into the $I_{\text {gain }}$ register.

$I_{\text {gain }}=\operatorname{int}\left(\frac{31251 \times I_{b}}{\text { Cur_mea }_{\text {mea }}}\right)$

Among them, $I_{\text {gain }}$ is the current gain coefficient. $I_{b}$ is a reference current. Cur_mea is the effective value of current measurement chip register value.

B. Clock calibration

The ML610Q495 has an internal real-time clock, so it does not require an external dedicated clock chip RTC. It has year, month, day and week date counting function, including the clock counting function of hours, minutes and seconds. It also has the range of choice for 0.5 seconds, one second and 1 minutes of periodic interrupt function, which is fully in line with the national grid and Southern Power Grid requirements. ML610Q495 has a successive comparison type $\mathrm{A} / \mathrm{D}$ converter, and built-in temperature sensor. Use the built-in temperature sensor with successive comparison type $\mathrm{A} / \mathrm{D}$ converter, temperature measurement can be realized by $-45^{\circ} \mathrm{C} \sim+90^{\circ} \mathrm{C}$. The detection accuracy can be achieved to $\pm 1^{\circ} \mathrm{C}$, which can be meted the National grid and Southern Power Grid requirements. The ML610Q495 has a built-in $1.9 \mathrm{~V}$ reference voltage, without using an external reference voltage.

The clock circuit. ML610Q495 chip only needs to use a small amount of device can realize the function of RTC. And the use of successive comparison type A/D converter with built-in temperature sensor detection can get the real-time temperature. We can compensate to RTC according to the collected temperature for temperature. The clock circuit is shown in Figure 2.

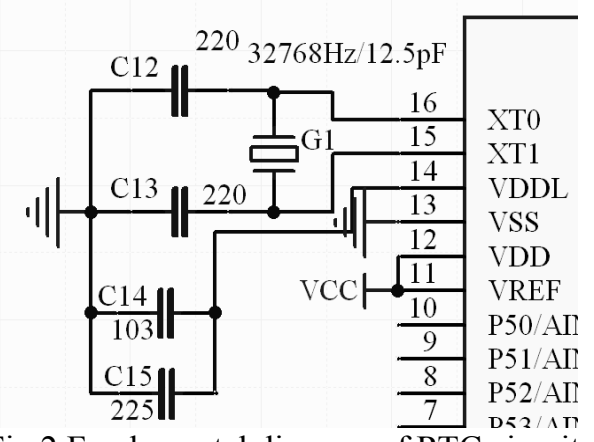

Fig.2 Fundamental diagram of RTC circuit

Clock calibration. Real time clock accuracy is only related to the $32768 \mathrm{~Hz}$ crystal oscillator. The frequency-temperature characteristic curve of the crystal 
oscillator is $T_{i}$ with the two vertices of the equation of a curve. The approximate formula of frequency, temperature characteristics is as follows:

$$
f_{-} \text {tem }=\beta(T-T i)^{2}
$$

Among them, $\beta$ is the two times the temperature coefficient, $T$ is an arbitrary temperature. $T_{i}$ is the top temperature.

Due to manufacturing process in the actual production process, we derived error curve through the above formula which is not consistent with the actual measurements. The actual frequency-temperature curve shows in Figure 3. The temperature curve is calculated by the formula shows in Figure4.

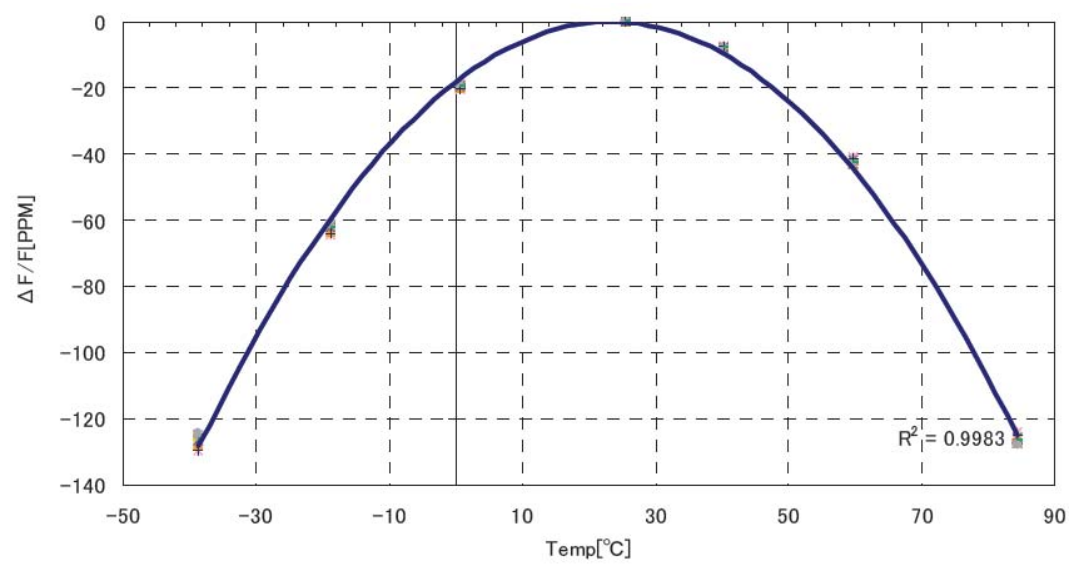

Fig.3 Fundamental diagram of RTC circuit

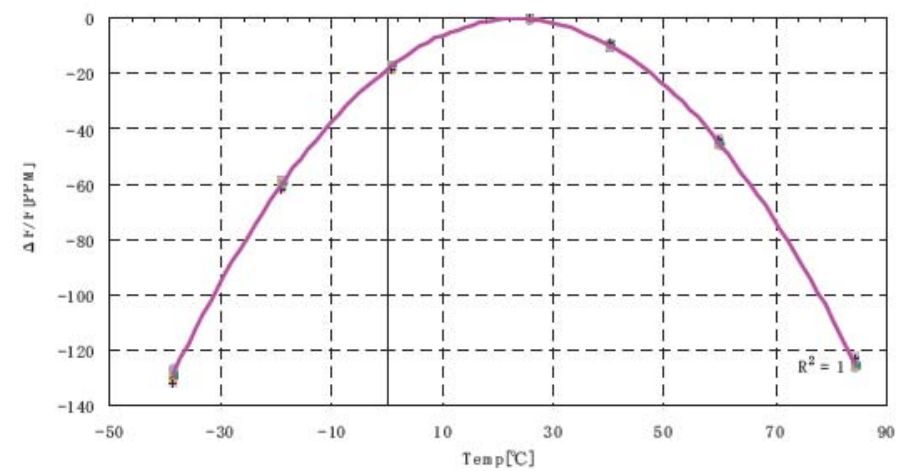

Fig.4 Fundamental diagram of RTC circuit

By bulk crystal oscillator detecting and calculating, it can be drawn that the existence of certain error between the measured frequency-temperature curve and the curve calculated by the formula 6 . It was shown in Figure 5 . 


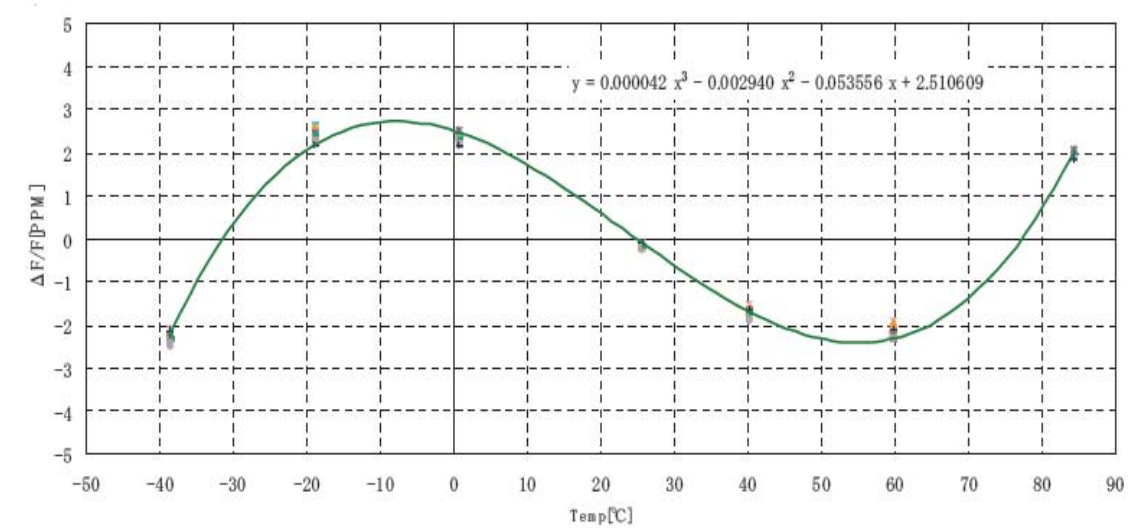

Fig.5 Fundamental diagram of RTC circuit

Combined with the measured value shown in the Figure 5 and the theoretical value of the error curve, the Coefficient increased three times based on the Eq.6, crystal frequency temperature curve was said in Eq.7.

$f \_$tem $=\beta(T-T i)^{2}+\gamma \times T^{3}$

Among them, $\gamma$ is triple coefficient, $\beta$ is quadratic coefficient, $T$ is an arbitrary temperature. $T_{i}$ is the top temperature.

In the program, crystal oscillator was temperature compensated in real time, according to Eq.7, which was called calibrate the clock error.

\section{Test Results}

After the meter was calibrated by 1 (100) $\mathrm{S}$ current specification measurement accuracy, we use the HS-6103F multi-function power meter calibration table for energy measurement error of the test, the test results shown in Table 1.

After the meter timing date error prospective completion, we use the HS-6103F multi-function power meter calibration table for meter calibration timing data error test, the test results are shown in Table 2.

Tab. 1 The test result of meter measuring accuracy

\begin{tabular}{cccccccccc}
\hline No. & $0.05 I_{b} 1$. & $0.1 I_{b} 1$. & $0.1 I_{b} 0$. & $1.0 I_{b} 1$. & $1.0 I_{b} 0$. & $0.5 I_{\max } 1$. & $0.5 I_{\max } 0$. & $I_{\max } 0$. & $I_{\max } 1$. \\
& $0 L$ & $0 L$ & $5 L$ & $0 L$ & $5 L$ & $0 L$ & $5 L$ & $5 L$ & $0 L$ \\
\hline $\begin{array}{c}\text { Mete } \\
\text { r1 }\end{array}$ & 28.86 & 28.33 & 3.700 & 0.000 & 9.194 & 1.014 & 207.25 & $\begin{array}{c}204.4 \\
0\end{array}$ & $\begin{array}{c}204.4 \\
0 \\
\text { Mete }\end{array}$ \\
r2 & 28.57 & 29.08 & 2.772 & 0.000 & 8.669 & 0.980 & 200.62 & $\begin{array}{c}204.6 \\
204.6\end{array}$ \\
\hline
\end{tabular}




\begin{tabular}{cccccccccc}
\hline $\begin{array}{c}\text { Mete } \\
\text { r3 }\end{array}$ & 28.33 & 28.36 & 1.465 & 0.000 & 9.220 & 1.014 & 208.10 & $\begin{array}{c}205.2 \\
8\end{array}$ & $\begin{array}{c}205.2 \\
8\end{array}$ \\
$\begin{array}{c}\text { Mete } \\
\text { r4 }\end{array}$ & 29.15 & 26.50 & 0.000 & 9.750 & 9.748 & 1.004 & 205.57 & $\begin{array}{c}204.7 \\
6\end{array}$ & $\begin{array}{c}204.7 \\
6\end{array}$ \\
$\begin{array}{c}\text { Mete } \\
\text { r5 }\end{array}$ & 29.39 & 26.64 & 0.000 & 9.467 & 9.463 & 0.980 & 200.62 & $\begin{array}{c}204.6 \\
2\end{array}$ & $\begin{array}{c}204.6 \\
2\end{array}$ \\
$\begin{array}{c}\text { Mete } \\
\text { r6 }\end{array}$ & 29.52 & 26.56 & 0.000 & 9.694 & 9.687 & 0.998 & 204.73 & $\begin{array}{c}205.1 \\
3\end{array}$ & $\begin{array}{c}205.1 \\
3\end{array}$ \\
\hline
\end{tabular}

Parameter monitoring of power equipment; Photovoltaic component; 1000W Battery: 2000Ah/24V; solar controller: $24 \mathrm{~V}_{\mathrm{DC}} / 1920 \mathrm{~W}$; Inverter: $2000 \mathrm{~W} / 220 \mathrm{~V}$

Tab.2 The test result of meter RTC accuracy

\begin{tabular}{ccccccccc}
\hline No. & $V_{\mathrm{p}} / \mathrm{V}$ & $V_{\mathrm{b}} / \mathrm{V}$ & $I_{\text {bin }} / \mathrm{A}$ & $I_{\text {bout }} / \mathrm{A}$ & $I_{\mathrm{c}} / \mathrm{A}$ & $I_{\mathrm{o}} / \mathrm{A}$ & $P_{\mathrm{c}} / \mathrm{W}$ & $V_{\mathrm{AC}} / \mathrm{V}$ \\
\hline Meter 1 & 28.86 & 28.33 & 3.700 & 0.000 & 9.194 & 1.014 & 207.25 & 204.40 \\
Meter 2 & 28.57 & 29.08 & 2.772 & 0.000 & 8.669 & 0.980 & 200.62 & 204.69 \\
Meter 3 & 28.33 & 28.36 & 1.465 & 0.000 & 9.220 & 1.014 & 208.10 & 205.28 \\
Meter 4 & 29.15 & 26.50 & 0.000 & 9.750 & 9.748 & 1.004 & 205.57 & 204.76 \\
Meter 5 & 29.39 & 26.64 & 0.000 & 9.467 & 9.463 & 0.980 & 200.62 & 204.62 \\
Meter 6 & 29.52 & 26.56 & 0.000 & 9.694 & 9.687 & 0.998 & 204.73 & 205.13 \\
\hline \multicolumn{7}{l}{ Parameter }
\end{tabular}

Parameter monitoring of power equipment; Photovoltaic component; 1000W

Battery: 2000Ah/24V; solar controller: $24 \mathrm{~V}_{\mathrm{DC}} / 1920 \mathrm{~W}$; Inverter: $2000 \mathrm{~W} / 220 \mathrm{~V}$

\section{Summary}

This paper describes the design of a wide range of intelligence-based ML610Q495 meter. The program has detected through the national grid, and mass production. The current specifications is 5 (60) A power meter calibration and the measurement accuracy is better than $\pm 0.1 \%$. In the range of $-45^{\circ} \mathrm{C} \sim$ $85^{\circ} \mathrm{C}$, the clock error is less, than $0.1 \mathrm{~s} / \mathrm{d}$, the performance indicators are higher than the national grid and the China Southern Power Grid requirements. Currently the meter was used in Liaoning, Jilin, Heilongjiang and other arctic regions and humid areas in Guizhou, Hainan are running well. It produced so much favorable comment from the load electric power bureau.

\section{References}

[1] FENG Yong-Jun, PU Zhi-Yong, JIANG Zi-song. Design of 1(100)A Single Phase High Accuracy Energy Meter Using 5000:1 Dynamic Range Metering IC[J], Electrical Measurement \& Instrumentation, 2011, 48(1): 50-55.

[2] HUANG Wei, YUAN Wei-wu, Using Power-comparison to Measure the 
Basic Error of Energy[J]. CHINA INSTRUMENTTATION. 2009,7: 70-73.

[3] Q/GDW 364-2009, Technical specification for single phase smart electricity meters[S], State Grid Co. Ltd, 2009.

[4] Integrated Device Technology, High-Performance Wide-Span Energy Metering IC 90E23[Z]. 2010.

[5] OKI Semiconductor Co, ML610Q495 User's Manual[Z], 2011.

[6] Chun-guang, YAO Li, Discussion on the Calibration of Harmonic Electrical Energy Meter[J]. Electrical Measurement \& Instrumentation. 2010, 47(529): 35-38.

[7] GUO Xing-xin, JIA Jun, GUO Xiaoyan, etc. Development and Application Prospect of Smart Electricity Meter[J]. Jiangsu Electrical Engineering.2012, 31(1): $82-84$

[8] SHAO Haiming. Research on the effects of carrier communication on smart meter metering error[D]. Beijing university of chirmed technology. 2013 